\title{
Measuring glacier outflows using a computerized conductivity system
}

\author{
GEOFF KITE \\ National Hydrology Research Institute, Saskatoon, Saskatchewan S7N 3H5, Canada
}

\begin{abstract}
The traditional method of calculating glacier outflows by measuring velocities and areas is difficult, inaccurate and sometimes dangerous in fast mountain streams. The salt-dilution method offers a more accurate alternative but, until now, its use has been restricted because of the difficulty of mixing chemical solutions and measuring chemical concentrations in the field. A computer program has been written which uses a laptop microcomputer to control measurements of stream conductivity and which quickly computes the stream flow directly in the field. The development of this method is described and examples are presented of the application of the method for glaciers in the Rocky Mountains and the Coast Mountains of Canada.
\end{abstract}

\section{INTRODUCTION}

The traditional velocity-area method of estimating flows by measuring velocity at a series of points along a crosssection is most appropriate in large rivers with uniform, steady flow. However, small mountain streams such as glacier outflows are usually turbulent and the velocityarea method becomes unsuitable because of the numerous approximations involved (Kite, 1989) and because of the basic design of the current meters commonly used (Kenney, 1977).

Fortunately, the rapid turbulent flows that make current meters unsuitable for mountain streams and glacier outflows are the ideal environment for dilution techniques of flow measurement. The basic principle of dilution gauging is the conservation of mass of some form of tracer. A known mass of tracer is introduced to the stream and its concentration is measured at some downstream point. The tracer may be introduced as a continuous source or as an "instantaneous" slug injection. Although other tracers such as radioactive isotopes, fluorescent dyes and microbiological agents have been used, sodium chloride $(\mathrm{NaCl})$ is the most common tracer used in North America.

The range of stream flow that may be measured using the dilution technique is limited by practical and environmental considerations to about $15 \mathrm{~m}^{3} \mathrm{~s}^{-1}$ (Church, 1973). However, by taking advantage of natural salt sources in tributary rivers, the dilution method can be extended to measure the flows of much larger rivers (Kite, 1989).

Other methods of dilution gauging require cumbersome and time-consuming mixing of accurately measured solutions and manpower-intensive measurement and calculation techniques (Benischke and Harum, 1990). However, at the comparatively low conductivities found in North American glacial streams, the concentration/ conductivity relationship can be considered linear (Kite, 1993). The introduction of compact conductivity meters and laptop computers enables the use of this relationship to improve measurement and computational accuracy in the field (Gees, 1990). This paper describes the development of a computerized dilution measurement system and its application in mountain streams and glacier outflows in Canada and the U.S.A. This new system obviates the need for preparation of solutions in the field and automates the computation of discharge.

\section{METHOD}

A slug of sodium chloride is injected into a stream and the concentration of the stream is monitored at some downstream point. From conservation of mass, the stream flow $Q\left(\mathrm{~m}^{3} \mathrm{~s}^{-1}\right)$ is calculated as:

$$
Q=\frac{M_{\mathrm{s}}}{\int_{0}^{T}\left(C_{t}-C_{0}\right) \mathrm{d} t}
$$

where $M_{\mathbf{B}}(\mathrm{kg})$ is the mass of $\mathrm{NaCl}$ injected, $T(\mathrm{~s})$ is the time of passage of the salt slug, $C_{t}\left(\mathrm{~kg} \mathrm{~m}^{-3}\right)$ is the concentration of $\mathrm{NaCl}$ in the river at time $t$ during the passage of the wave and $C_{0}\left(\mathrm{~kg} \mathrm{~m}^{-3}\right)$ is the natural concentration of salts in the river before addition of the salt slug.

In practice, it is easier and more convenient to compute the stream flow from conductivity instead of concentration, so that:

$$
Q=\frac{1000 M_{8} \Gamma_{\mathrm{g}, 25}}{t \sum\left(L_{\mathrm{r}}-L_{0}\right)}
$$

where the integral has been replaced by a summation, $t$ is the sampling interval in seconds, $L_{\mathrm{r}}$ is the recorded conductivity in $\mu \mathrm{S} \mathrm{cm}^{-1}$ and $L_{0}$ is the natural conductivity of the river in the same units. $\Gamma_{\mathrm{g}, 25}$ is the 
gram-conductivity of $\mathrm{NaCl}$ (i.e. the conductivity, in $\mu \mathrm{S} \mathrm{cm}^{-1}$, of $1 \mathrm{~g}$ of $\mathrm{NaCl}$ in $1 \mathrm{~m}^{3}$ of solution at $25^{\circ} \mathrm{C}$ ) and is used to convert the measured conductivity into units of concentration needed for the mass balance.

In the field, conductivity is measured by a fourelectrode sensor using an induced alternating current in a closed loop. The magnitude of the induced current is proportional to the conductance of the solution. The sensor also measures temperature and converts the conductivity to $25^{\circ} \mathrm{C}$ equivalent. The output from the sensor is converted to digital form and transferred to the RS-232C port on a laptop microcomputer. The equipment used is shown in Figure 1.

A stream-flow measurement consists of the following steps:

1. Before going into the field, the user weighs convenient amounts of dry sodium chloride into sealed plastic bags. Masses of $1 \mathrm{~kg}$ have been found convenient.

2. In the field, the user loads a computer program into the laptop microcomputer. The program is written in FORTRAN, occupies about 60 kbytes as a compressed executable and is suitable for use on any DOS microcomputer. The program uses menus and windows to guide the user through the measurement. From the opening menu, the user is guided to check and, if necessary, correct the microcomputersystem time and date. All data input to the computer by the user or by the probe will be labeled with a date and time, and recorded in a log file.

3. The user is then prompted to place the sensor in the centre of the stream at about mid-depth. The program will take ten temperature measurements at $2 \mathrm{~s}$ intervals and records the average.

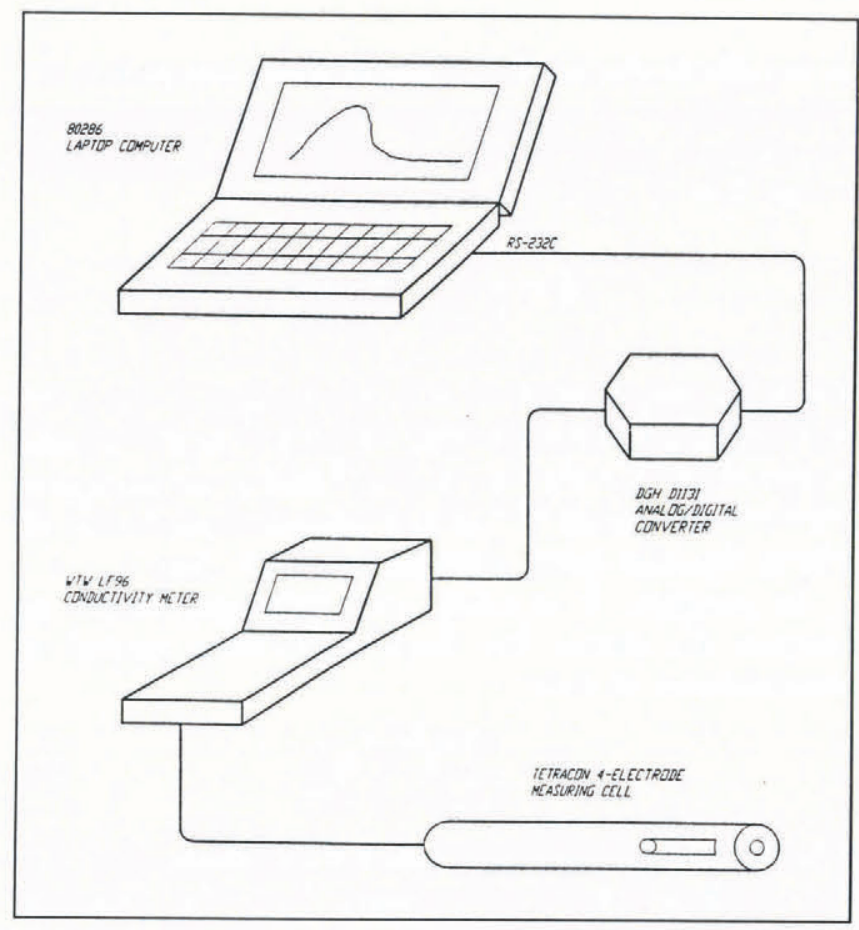

Fig. 1. Equipment used for conductivity measurements.
4. Next, the user is prompted to set a suitable scale on the conductivity meter. The program then computes and records the natural background conductivity of the river using an average of ten readings at $2 \mathrm{~s}$ intervals.

5. The program prompts the user for estimates of stream width, depth and velocity, and displays an estimate of the mass of salt needed for the flow measurement. This mass $M_{\mathbf{B}}$ is estimated from the experimental relationship (Kite, 1993):

$$
M_{\mathrm{s}}=0.13 \delta_{\mathrm{c}} A^{\frac{3}{2}}
$$

where $\delta_{\mathrm{c}}$ is the required rise in conductivity in $\mu \mathrm{S} \mathrm{cm}^{-1}$ (the program assumes this is $50 \%$ of the background conductivity) and $A\left(\mathrm{~m}^{2}\right)$ is an estimated stream crosssectional area. The figure of $50 \%$ is deliberately very conservative in order to ensure good separation from the background conductivity; experienced operators may use lower figures to conserve salt.

In practice, the program first calculates a mixing length $L_{\mathrm{m}}(\mathrm{m})$ from the experimental relationship

$$
L_{\mathrm{m}}=260 \sqrt{A},
$$

displays this for the user's information in selecting a river reach, and then uses $L_{\mathrm{m}}$ to estimate $M_{\mathrm{s}}$. It should be emphasized that the figures calculated for mixing length and mass of salt are estimates only, since no general mathematical relationships are available; a comparison with other formulae for mixing length has been given in Kite (1993). The program has a lower limit of $0.5 \mathrm{~kg}$ for $M_{8}$. This lower limit has been shown appropriate for streams in the Rocky Mountains but, in Europe, lower values are used (personal communication from R. Benischke, 1992).

6. The field worker selects a mass of salt to use based on the program's estimate of needs and on the available selection of pre-weighed bags of salt and, if necessary, changes the default value calculated by the program.

7. The program then prompts the user to start recording conductivity and to inject the slug of salt at a distance upstream at least equal to the mixing length. The computer will record the salt wave (Fig. 2), remove the effect of background conductivity, compute the area beneath the remaining curve and calculate the discharge. The start of the salt wave is determined as the point at which two consecutive measurements are at least two standard deviations above the background conductivity. The end of the salt wave is determined as the point at which two consecutive measurements are within two standard deviations of the initial background conductivity. The effect of the background conductivity is then taken as the area within the quadrilateral between the start and end points and the line of zero conductivity. This accounts for any small change in background conductivity which may have taken place during the measurement. All the data are recorded in a dated log file for later review. 


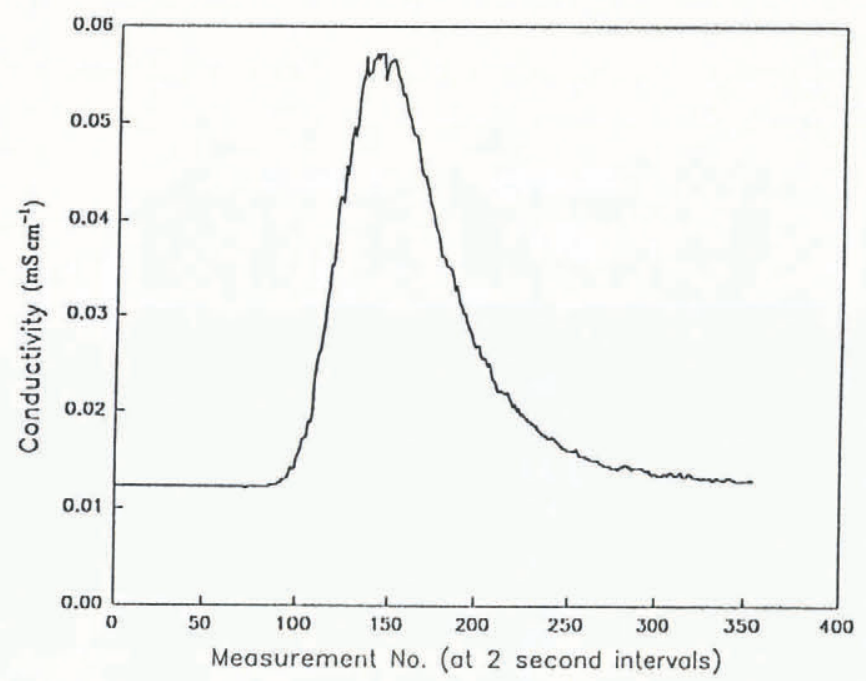

Fig. 2. River conductivity during a dilution measurement, Sentinel Creek.

\section{RESULTS}

Measurements using the salt-dilution method are compared to simultaneous current-meter measurements or with stream flows computed from previously established rating curves for mountain streams and glacier outflows in Alberta, British Columbia and Wyoming in Table 1.

Exact comparisons are difficult because of the inaccuracy of current meters at low flows and the consequent errors in rating curves but, with the exception of measurements at Nash Fork and Little Red Deer River, the results are in good agreement.

Since most glacier outflows are not permanently gauged, it was of interest to see whether the computerized salt-dilution method could be used to establish rating curves. Figures 3 and 4 show curves developed for the outflows from Sentinel and Place Glaciers in the Coast Mountains of British Columbia. Table 2 clearly demonstrates the repeatability of the measurements.

The measurement program at Place Glacier was also used to investigate the effect of using slugs of coarse- and fine-grained solid salt (last column in Table 2). Figure 4 shows that using coarse-grained salt gave slightly $(<5 \%)$

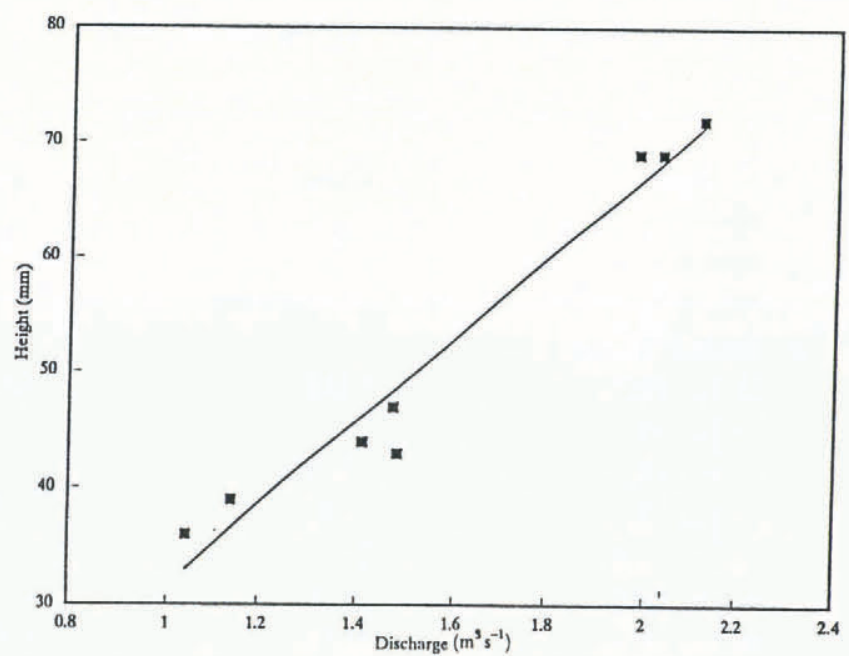

Fig. 3. Rating curve for Sentinel Creek.

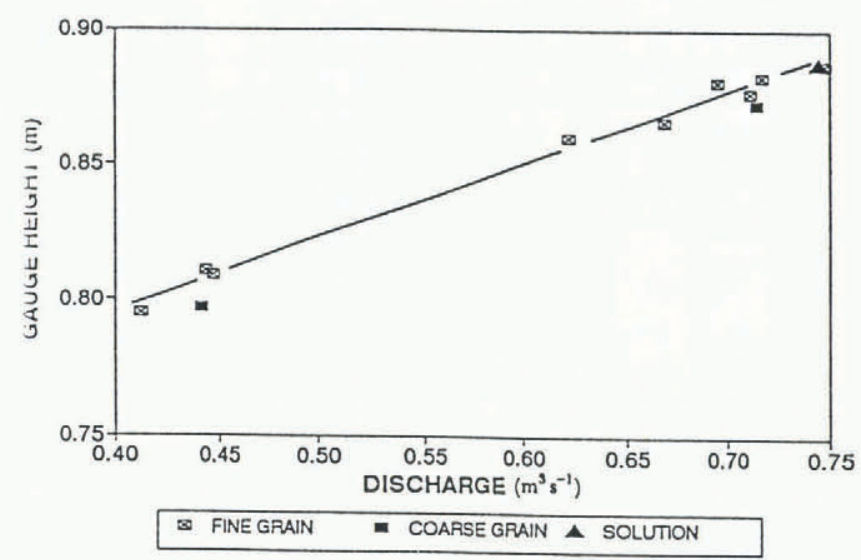

Fig. 4. Rating curve for Place Creek.

higher estimates of stream flow because the salt was slower to dissolve and gave a more prolonged, less distinct, wave. For reference, one measurement was made using the conventional salt solution; no significant difference in accuracy was found.

Further series of measurements were made at Sphinx, Upper Garibaldi and Lower Barrier Glaciers but they are not given here.

Table 1. Summary of measured stream flows

Stream or glacier

Date

Background conductivity Measured stream flow

$$
\mu \mathrm{S} \mathrm{cm}^{-1}
$$

$\mathrm{m}^{3} \mathrm{~s}^{-1}$

Stream flow from current meter or rating curve* $\mathrm{m}^{3} \mathrm{~s}^{-1}$
Jumping Pound

McGillivray

Castle Creek

Nash Fork

Nash Fork

Trap Creek

Sheep River

Little Red Deer
11 Jun 1991

13 Jun 1991

13 Jun 1991

4 Sep 1991

5 Sep 1991

27 Sep 1991

27 Sep 1991

28 Sep 1991
197

224

114

110

113

360

341

415
0.88

2.02

0.18

0.03

0.05

0.75

2.58

1.32
0.92

1.92

0.15

0.04

0.07

0.85

2.60

$0.77^{\circ}$

Stream flows are from current meter except for ${ }^{*}$ which is from a rating curve. 


\begin{tabular}{lccll}
\hline Date & Time & Stage & Discharge \\
& $\mathrm{h}$ & $\mathrm{m}$ & Comment \\
& & & \\
$\mathrm{m}^{3} \mathrm{~s}^{-1}$ & \\
\hline a. Sentinel Glacier & 1215 & 0.036 & 1.04 & \\
23 Jul 1991 & 1445 & 0.047 & 1.47 & \\
23 Jul 1991 & 1525 & 0.069 & 2.03 & \\
25 Jul 1991 & 1545 & 0.069 & 1.98 & \\
25 Jul 1991 & 2015 & 0.072 & 2.12 & \\
25 Jul 1991 & 1120 & 0.044 & 1.41 & \\
26 Jul 1991 & 1140 & 0.043 & 1.48 & \\
26 Jul 1991 & 0955 & 0.039 & 1.14 & \\
5 Aug 1991 & & & & \\
b. Place Glacier & 1620 & 4.160 & 0.623 & Fine grain \\
7 Oct 1991 & 1642 & 4.166 & 0.668 & Fine grain \\
7 Oct 1991 & 1730 & 4.173 & 0.715 & Coarse \\
7 Oct 1991 & 1757 & 4.177 & 0.712 & Fine \\
7 Oct 1991 & 1823 & 4.180 & 0.695 & Fine \\
7 Oct 1991 & 1848 & 4.183 & 0.718 & Fine \\
7 Oct 1991 & 1957 & 4.187 & 0.748 & Fine \\
7 Oct 1991 & 2013 & 4.188 & 0.745 & Solution \\
7 Oct 1991 & 0925 & 4.112 & 0.443 & Fine \\
8 Oct 1991 & 0943 & 4.110 & 0.447 & Fine \\
8 Oct 1991 & 1237 & 4.098 & 0.441 & Coarse \\
8 Oct 1991 & 1302 & 4.096 & 0.412 & Fine \\
8 Oct 1991 & & & & \\
\hline
\end{tabular}

\section{DISCUSSION}

Salt dilution is a more suitable method of measuring glacier outflows where the stream flow is rapid and turbulent, and the traditional current meter is least accurate. A computerized measurement system using conductivity has been developed which, by using sodium chloride granules, has eliminated the need for manual preparation of chemical solutions in the field and has made the measurement procedure quick and easy.

The procedure is controlled by a computer program which, run on a laptop microcomputer, guides the user through the procedure, takes all the measurements needed and computes the stream flow within a few seconds. The method and the equipment developed have been tested in Canada and the U.S.A., and gave results which compare with simultaneous current-meter measurements and with data from rating curves.

The cost of the measuring equipment is approximately:

$\begin{array}{ll}\text { Conductivity meter and probe } & \text { US } \$ 980 \\ \text { Analogue/digital converter } & \text { US } \$ 300 .\end{array}$

On top of this would be the cost of a laptop microcomputer. This total cost is comparable to that of a conventional current-meter set and will provide an expanded capability for data-collection agencies and field workers.
The computer program is available from the author at no cost by sending a blank diskette.

\section{ACKNOWLEDGEMENTS}

Conductivity measurements at Sentinel and Place Glaciers were made by $\mathrm{H}$. Laudon and at the Nash Fork of the Little Laramie River by C. Senft. The author wishes to acknowledge the useful comments made by $\mathrm{Dr}$ R. Benischke and by an anonymous referee.

\section{REFERENCES}

Benischke, R. and T. Harum. 1990. Determination of discharge rates in turbulent streams by salt tracer dilution applying a microcomputer system. Comparison with current meter measurements. International Association of Hydrological Sciences Publication 193 (Symposia at Lausanne 1990 - Hydrology in Mountainous Regions. I), 215-221.

Church, M. 1973. Some tracer techniques for streamflow measurements. Tech. Bull. Br. Geomorphol. Res. Group.

Gees, A. 1990. Flow measurement under difficult measuring conditions: field experience with the salt dilution method. International Association of Hydrological Sciences Publication 193 (Symposia at Lausanne 1990 Hydrology in Mountainous Regions. I), 255-262.

Kenney, B.C. 1977. Response characteristics affecting the design and use of current direction vanes. Deep-Sea Res., 24, 289-300.

Kite, G.W. 1989. An extension to the salt dilution method of measuring streamflow. Wat. Res. Devel., 5(1), 19-24.

Kite, G.W. 1993. Computerized streamflow measurement using slug injection. Hydrological Processes., 7, 227-233.

The accuracy of references in the text and in this list is the responsibility of the author, to whom queries should be addressed. 